\title{
OS PROJETOS DE TRABALHO E A AVALIAÇÃO FORMATIVA
}

\author{
Marília Ramalho D. NESSRALLA ${ }^{1}$ \\ Doutoranda em Estudos Linguísticos \\ Universidade Federal de Uberlândia
}

RESUMO: Este artigo discute os aspectos envolvidos na realização de um projeto de trabalho e sua relação com a avaliação formativa. Para enfatizar o caráter processual da avaliação, utilizamos o termo ensino-avaliação-aprendizagem, defendendo a utilização de rubricas nesse processo avaliativo. O projeto de trabalho foi desenvolvido nas aulas de Língua Inglesa em uma turma de ensino médio integrado. Os projetos de trabalho são uma estratégia que deve propiciar a análise, a interpretação e a crítica das questões relevantes (HERNÁNDEZ, 1998) e relacionadas a outros temas e ao fazer significativo (LUDKE, 2003). A realização dos projetos de trabalho está prevista nas orientações curriculares para o ensino médio no Brasil. $\mathrm{O}$ tema do projeto foi a família e a escola, assuntos estudados no semestre. O desenvolvimento do projeto foi realizado em três etapas. A primeira etapa foi a preparação dos alunos para a entrevista com os colegas. A segunda etapa foi o levantamento de dados a partir das entrevistas. A terceira etapa foi a apresentação dos dados para a turma. A realização da atividade proporcionou um estudo interdisciplinar, o desenvolvimento do letramento crítico e da produção oral e escrita dos alunos

PALAVRAS-CHAVE: Projetos de Trabalho; Avaliação Formativa; Língua Inglesa.

ABSTRACT: This article discusses the issues involved in the achievement of a work project and its relationship to formative assessment. To emphasize the procedural nature of the evaluation, we use the term teaching-evaluation-learning, advocating the use of rubrics in this evaluation process. The work project was developed in the English classes at a vocational high school. The work projects are a strategy that should provide the analysis, interpretation and criticism of relevant issues (Hernández, 1998) which could be related to other topics and to meaningful activities (LUDKE, 2003). The completion of work projects is planned in the curriculum guidelines for high school in Brazil. The project theme was about family and school, topics studied in the semester. The development of the project was carried out in three stages. The first step was the preparation of students for the interview with classmates. The second stage was the collection of data from the interviews. The third step was the presentation of data to the class. The fulfillment of the activity provided an interdisciplinary study, the development of critical literacy and oral and written production of students.

KEYWORDS: Work Projects; Formative Assessment; English Language.

\section{Introdução}

\footnotetext{
${ }^{1}$ Agência Financiadora: CAPES.
} 
Relatar sobre as nossas experiências em sala de aula nos faz avaliar esse processo de forma retrospectiva, prospectiva, introspectiva e extrospectiva, em seus aspectos práticos e teórico-metodológicos. Assim, ao trazer, nesse artigo, a experiência sobre a realização de um projeto, que desenvolvemos com alunos do primeiro ano do ensino médio integrado ${ }^{2}$ em uma escola da rede pública federal, tecemos considerações sobre os projetos de trabalho como possibilidade de avaliação formativa. Primeiramente, então, apresentamos os fundamentos teórico-metodológicos dos projetos de trabalho, que partem sempre de um tema, vinculado ao fazer significativo (HERNÁNDEZ, 1998; BRASIL, 2002; LUDKE, 2003), a avaliação formativa como utopia promissora (HADJI, 2001), e orientada para a qualidade dos processos e dos resultados (ÁLVAREZ MÉNDEZ, 2002), relacionando esses estudos aos documentos oficiais que norteiam o ensino médio brasileiro (BRASIL, 2011; 2006, 2002, 1996/2013). Em seguida, apresentamos as etapas de desenvolvimento do projeto de trabalho realizado, os resultados no processo ensino-avaliação-aprendizagem obtidos em sala de aula. Finalizamos com uma autoavaliação do processo vivido, apontando acertos e desacertos no projeto desenvolvido.

\section{Os Projetos e a Avaliação Formativa}

Sem a pretensão de esgotar o termo e alertando que os projetos não são panaceias, mas uma forma de se buscar alcançar a aprendizagem significativa e atender à função essencial da escola de formar cidadãos, Ludke (2003) aponta as características básicas de um projeto. Para a autora, essas características são: (i) a possibilidade do trabalho interdisciplinar, pois os temas extrapolam as fronteiras das disciplinas, requerendo tanto do professor quanto dos alunos uma busca por várias fontes de informação até em outros campos do conhecimento; (ii) a otimização do aproveitamento dos conteúdos pelos alunos; (iii) o estímulo à participação ativa dos alunos, articulando o conhecimento anterior com os novos conhecimentos e desenvolvendo, assim, uma atitude de pesquisa nos mesmos; (iv) a necessidade de colaboração entre os próprios colegas, articulando, dessa forma, o esforço do trabalho individual e coletivo; e (v) a integração das atividades do projeto com os objetivos de formação delineados no projeto pedagógico da instituição.

Lembramos que Ludke (2003) argumenta que os projetos buscam enfocar um problema, que está relacionado a outros temas, "sem esgotar os conhecimentos oferecidos pelas disciplinas, mas servindo-se deles de maneira criativa, em elaborações próprias aos níveis de desenvolvimento dos alunos envolvidos" (LUDKE, 2003, p.71-72). No projeto que desenvolvemos e que relatamos neste texto, o tema foi proposto pelo livro didático, dentro dos assuntos abordados no semestre estudado, quais sejam, a família e a escola.

Para Hernández (1998), os projetos de trabalho, termo que adotamos neste artigo, proporcionam a possibilidade de construção da própria identidade, pois os alunos estabelecem relações com diferentes experiências culturais e com conhecimentos relevantes para eles. Dessa forma, a escola pode se tornar inclusiva, ao ser um local em que os alunos podem escrever a própria história.

\footnotetext{
${ }^{2}$ Curso do ensino médio com a educação profissional técnica de nível médio, considerado como matrícula única.
} 
O autor supracitado enfatiza que os projetos de trabalho não são um método, mas uma estratégia na qual não há um itinerário único. Ao serem desenvolvidos a partir de um temaproblema, os projetos de trabalho devem propiciar a análise, a interpretação e a crítica das questões relevantes, ao evidenciar diferentes aspectos e opiniões do tema-problema, pois professores e alunos trabalham com diferentes fontes de informação e ambos são aprendizes nesse processo.

Outro aspecto destacado pelo referido autor é que as diferentes formas de aprender, as diferentes capacidades e habilidades são consideradas, ou seja, o princípio é o de que todos são capazes de aprender. E a aprendizagem não fica restrita apenas ao tema-problema, pois ao abranger problemas de outras disciplinas, os alunos poderão aprender assuntos além do que foi planejado. O autor descreve, assim, "O que poderia ser um projeto de trabalho":

1.Um percurso por um tema-problema que favorece a análise, a interpretação e a crítica (como contraste de pontos de vista). 2.Onde predomina a atitude de cooperação e o professor é um aprendiz, e não um especialista (pois ajuda a aprender sobre temas que irá estudar com os alunos). 3.Um percurso que procura estabelecer conexões e que questiona a ideia de uma versão única da realidade. 4.Cada percurso é singular, e se trabalha com diferentes tipos de informação. 5.0 docente ensina a escutar; do que os outros dizem, também podemos aprender. 6. Há diferentes formas de aprender aquilo que queremos ensinar (e não sabemos se aprenderão isso ou outras coisas). 7. Uma aproximação atualizada aos problemas das disciplinas e dos saberes. 8. Uma forma de aprendizagem na qual se leva em conta que todos os alunos podem aprender, se encontrarem o lugar para isso. 9. Por isso, não se esquece que a aprendizagem vinculada ao fazer, à atividade manual e à intuição também é uma forma de aprendizagem (HERNÁNDEZ, 1998, p.82).

Considerando essas questões envolvidas no desenvolvimento de um projeto de trabalho, apontamos que elas estão relacionadas à realização da avaliação formativa, denominada por Hadji (2001) de utopia promissora, por ser um modelo ideal de avaliação. O autor em pauta esclarece que a avaliação formativa não precisa se conformar a nenhum padrão metodológico, porque é a intenção predominante do avaliador que determina esse caráter formativo. Por meio desse tipo de avaliação, o professor irá adequar a sua ação pedagógica e o aluno poderá ficar ciente dos seus erros e procurar corrigi-los. É uma avaliação inclusiva, em que prevalece o caráter qualitativo sobre o quantitativo. Nesse sentido, mesmo uma avaliação somativa pode adquirir um caráter formativo, se o professor a utilizar como forma de regulação da aprendizagem dos alunos.

Por sua vez, Álvarez Méndez (2002) pondera que a avaliação está intimamente relacionada à natureza do conhecimento. Por isso é importante o professor conhecer a diferença entre a visão positivista do conhecimento, que o entende como constituído basicamente pelos fatos, pelos dados empíricos, como algo externo e alheio ao sujeito, da visão sócio-histórico-cultural do conhecimento. Esta segunda perspectiva reconhece a participação ativa dos sujeitos. Então a tarefa do professor é despertar nos alunos a curiosidade por aprender e ajudá-los a sentir, agir e internalizar as normas e os critérios para julgar o que torna diferente o seu conteúdo. A avaliação formativa é a forma de avaliação voltada para a qualidade do processo de aprendizagem e para seus resultados. Ela está a serviço da prática para melhorá-la, sendo contínua, processual. Tal postura implica que avaliar 
o aluno somente ao final de determinada unidade estudada apenas o classifica. No entanto, se a avaliação for um exercício permanente, o sucesso do aprendiz será parte integrante do processo de aprendizagem. Ressaltamos, portanto, que as atividades de desenvolvimento de um projeto devem ser avaliadas dentro dessa perspectiva processual, e os critérios de avaliação devem ser conhecidos com antecedência pelos alunos.

Ludke (2003) propõe que os projetos de trabalho sejam avaliados por rubricas. Concordando com a autora em pauta sobre o fato de que se o uso do termo rubrica é novo, é antiga a inquietação dos professores em buscar instrumentos "que possam atender às necessidades de seus alunos, reconhecendo suas diferenças, atentos ao fato de que muitas vezes o currículo e os padrões estabelecidos não dão conta delas" (LUDKE, 2003, p.76). As rubricas se concretizam, assim, como uma "ponte entre o que se propõe e o que se espera (e como se espera), deixando claro o compromisso assumido pelos alunos e pelo professor, frente a cada situação de trabalho" (LUDKE, 2003, p.75). As rubricas são critérios específicos, construídos para avaliar cada projeto, atividade, pesquisa, produção do aluno. É de primordial importância que o professor tenha clareza sobre quais aspectos ele irá avaliar no trabalho do aluno. Não há, nas rubricas, o intuito de avaliar o aluno de acordo com padrões de medida de larga escala, como o sistema de avaliação em nível nacional, tipo o SAEB, Sistema de Avaliação da Educação Básica, ou o ENEM, Exame Nacional do Ensino Médio no Brasil. Entretanto, estudos comprovam que, quanto mais o aluno é avaliado na perspectiva formativa, melhor é o rendimento dele em testes de larga escala (FERNANDES, 2015), pois a avaliação formativa tem como objetivo a aprendizagem. Por isso, para ressaltar o caráter processual da avaliação e por entender que a avaliação está a serviço da aprendizagem, utilizamos o termo ensinoavaliação-aprendizagem (SILVA, 2006; FELICE, 2013; FIDALGO, 2015; NESSRALLA, 2016).

\section{A avaliação formativa e os projetos de trabalho na legislação do ensino médio}

Nesta seção, discutiremos o que dizem os documentos oficiais sobre os temas abordados neste artigo, quais sejam, a avaliação formativa e os projetos de trabalho. Esses documentos são: a Lei de Diretrizes e Bases da Educação Nacional 9394/1996, e alterações, LDB (BRASIL, 2013), os Parâmetros Curriculares Nacionais, PCN+ Ensino Médio (BRASIL, 2002), as Orientações Curriculares do Ensino Médio, OCEM (BRASIL, 2006), e as Diretrizes Curriculares Nacionais do Ensino Médio, DCNEM (BRASIL, 2011).

A LDB 9394/1996 (BRASIL, 2013) preconiza, em seu Artigo 24, Inciso V, que a verificação do rendimento escolar observará os seguintes critérios: a) avaliação contínua e cumulativa do desempenho do aluno, com prevalência dos aspectos qualitativos sobre os quantitativos e dos resultados ao longo do período sobre os de eventuais provas finais [...] e, no Artigo 36, Inciso II, que o Currículo do Ensino Médio adotará metodologias de ensino e de avaliação que estimulem a iniciativa dos estudantes (BRASIL, 2013).

As Diretrizes Curriculares Nacionais para o Ensino Médio, DCNEM, apontam os princípios pedagógicos estruturadores dos currículos, quais sejam, da identidade, da diversidade, da autonomia, da interdisciplinaridade e da contextualização. Tais princípios devem levar os educadores a considerarem a juventude como uma condição sócio-históricocultural, superando uma visão homogeneizante e naturalizada do estudante. O documento 
ainda ressalta que essa categoria social convive com as incertezas do futuro, com sua necessidade de se fazer ouvir e sua valorização da sociabilidade. Constitui um desafio para o país enfrentar o baixo índice - 50,9\% - de conclusão do ensino médio (BRASIL, 2011). Esse nível de ensino é tido como um dos pilares para a sustentação do desenvolvimento que o país tem experimentado nos últimos anos (BRASIL, 2011b). Segundo Amin Aur e Castro (2012, p.16), este baixo índice de conclusão do ensino médio deve-se ao fato de que a "educação escolar torna-se desinteressante, pois não corresponde aos variados anseios, aspirações e necessidades dos jovens em sua complexa e diversificada constituição". Dito em outros termos, os princípios das DCNEM se coadunam com os pilares da avaliação formativa e do desenvolvimento de projetos de trabalho, ao se assentarem sobre a construção da própria identidade, proporcionando aos jovens um aprendizado significativo, contextualizado, que faça sentido para as suas vidas.

Os PCN+ Ensino Médio (BRASIL, 2002), ao se apoiarem no conceito de conhecimento como construção coletiva e dinâmica, indicam o trabalho por projetos e a interdisciplinaridade no ensino de língua estrangeira como possibilidade de levar o aluno a desenvolver competências estratégicas, gramaticais, discursivas e sociolinguísticas. O documento sinaliza que é da competência do grupo de professores da instituição escolar propiciar "situações-desafio e projetos que sejam mobilizadores e dirigidos para aprendizados específicos variados e estimulantes", mesmo que "aprendizados não previstos no projeto surjam ao longo do processo" (BRASIL, 2002, p. 121). Outro aspecto importante ressaltado no documento é que, nas situações-desafio, o professor deve proporcionar o apoio apropriado durante o processo para evitar que os alunos se sintam impotentes e desanimados devido a uma dificuldade que pode ser intransponível num dado momento, impedindo o aprendizado.

Em relação à avaliação formativa, os $\mathrm{PCN}+$ Ensino Médio reconhecem os diversos entraves materiais e institucionais que bloqueiam o seu uso no cotidiano das escolas, tais como: "o número de alunos por classe, a extensão dos programas, o horário escolar, a proposta curricular, a carência de recursos materiais e a formação dos professores" (BRASIL, 2002, p.124). Embasado em Perrenoud ${ }^{3}$ (1999), o texto legal destaca as características da avaliação formativa:

deve incluir apenas tarefas contextualizadas; deve referir-se a problemas complexos; deve contribuir para que os alunos desenvolvam ainda mais suas competências; exige a utilização funcional de conhecimentos disciplinares; pressupõe que as tarefas e suas exigências sejam conhecidas pelos alunos antes do início do trabalho; exige uma certa forma de colaboração entre pares; inclui a auto-avaliação (BRASIL, 2002, p.126).

Por sua vez, as Orientações Curriculares Nacionais para o Ensino Médio, OCEM, privilegiam a avaliação formativa, contínua, de acompanhamento, orientando o professor a considerar o erro do aluno como fonte de aprendizagem e de redirecionamento do programa do curso, de acordo com as necessidades dos aprendizes. A avaliação, dessa forma,

deve utilizar diferentes instrumentos, tanto para o diagnóstico do progresso do aluno quanto para a mensuração dos resultados alcançados em determinado

\footnotetext{
${ }^{3}$ PERRENOUD, P. Avaliação: entre duas lógicas. Porto Alegre: Artmed, 1999.
} 
momento, e deve revestir-se de um caráter positivo de modo a trazer à tona o potencial que o aprendiz tem para avançar no seu estudo da língua estrangeira (BRASIL, 2006, p. 143).

No entanto, conforme observa Fidalgo (2015), que analisou as orientações curriculares de seis estados brasileiros, observamos que nem os PCN+, nem as OCEM explicitam ao professor como elaborar instrumentos de avaliação formativa. Assim, "cabe sempre ao professor transformar a teoria em prática na hora de avaliar - o que é bastante desafiador, já que a teoria em si não é fácil de compreender e aplicar" (FIDALGO, 2015, p. 297).

Outra possibilidade de avaliação formativa que os documentos oficiais não abordam é a co-avaliação ou avaliação dos pares. Nesse tipo de avaliação, os alunos avaliam os próprios colegas, a partir, sempre, de critérios conhecidos por todos os envolvidos no processo. A coavaliação propicia o desenvolvimento da autonomia, ao conduzir os alunos a se responsabilizarem em gerenciar a sua própria aprendizagem. Ao aprenderem a avaliar o colega, os alunos poderão participar mais da aula, se interessando mais pelo conteúdo e pelas atividades propostas, pois eles sabem que também serão objeto de avaliação pelos colegas.

\section{Percurso do projeto desenvolvido}

O projeto de trabalho Our families: a Class Survey que apresentamos neste texto foi desenvolvido com alunos do $1^{\circ}$ ano do ensino médio integrado, como uma atividade prevista no livro didático Freeway (RICHMOND EDUCAÇÃO, 2010). A coleção faz parte do Programa ${ }^{4}$ Nacional do Livro Didático, PNLD/2012 do ensino médio, e foi escolhida por nós, professores da instituição.

O PNLD do ensino médio foi instituído em 2003. No entanto, os livros de língua estrangeira - inglês e espanhol - foram incluídos a partir do PNLD de 2012. Os livros foram distribuídos na versão consumível, com CD. As coleções aprovadas no PNLD trazem uma variedade de práticas discursivas e a incorporação de diferentes gêneros orais e escritos (PAIVA, 2012). O estudo da língua pela incorporação de diferentes gêneros é proposto nos PCN+ Ensino Médio (BRASIL, 2002). No projeto de trabalho desenvolvido, o gênero estudado foi a entrevista.

Apesar de termos vivenciado uma certa dificuldade em utilizar o livro adotado devido a algumas incoerências na obra, tais como atividades gramaticais sem um propósito comunicativo, a coleção apresentava temas interdisciplinares sobre a vida contemporânea e conectados ao mundo dos alunos. Esses temas podem auxiliar o professor a trabalhar o desenvolvimento do letramento crítico com os alunos, conforme proposto nas OCEM, pois são temas relevantes à realidade sociocultural do aluno. $\mathrm{O}$ primeiro projeto proposto neste

\footnotetext{
${ }^{4}$ A distribuição de livros didáticos, como política pública no Brasil, teve início em 1929, com a criação do Instituto Nacional do Livro. Eram contemplados apenas os alunos das séries iniciais do ensino fundamental. Posteriormente, a partir de 1983, é que os livros didáticos passaram a ser distribuídos às demais séries do ensino fundamental. Depois de outras denominações, o programa passou a ser intitulado "Programa Nacional do Livro Didático, PNLD”, em 1985. (BRASIL, 2012).
} 
livro para o primeiro ano relacionava-se aos temas trabalhados no semestre com os alunos, a saber, a família e a escola. De acordo com os autores do livro,

os projetos buscam propiciar produções textuais variadas e divulgá-las entre os alunos. Assim, a prática da escrita não se limita a provar que aprenderam a utilizar os conhecimentos linguísticos e textuais trabalhados anteriormente, mas expande-se para o universo de experimentação da criação textual, da autoria e da expressão individual das apropriações feitas ao longo dos estudos no idioma estrangeiro (RICHMOND EDUCAÇÃO, 2010, p.5-6).

Os autores alertavam o professor de evitar que a atividade se tornasse discriminatória ou preconceituosa caso houvesse pais de alunos com poucos anos de formação escolar ou analfabetos ou ainda, famílias formadas de maneira não tradicional. Também propunha que o professor discutisse com os alunos as razões que levam uma pessoa a abandonar os estudos e os motivos que contribuem para que ela conclua ou não o curso superior, além da reflexão sobre se essas escolhas poderiam variar no nosso país, de acordo com a região geográfica, a classe social, a faixa etária e as escolhas profissionais.

Para os autores do livro, a finalidade do projeto era "aplicar os conhecimentos lexicais relacionados à família e à escola, numa pesquisa envolvendo a turma toda" (RICHMOND EDUCAÇÃO, 2010, p.19). No entanto, como um dos objetivos do nosso programa de ensino é a competência discursiva, estabelecemos como objetivo específico do projeto produzir textos orais e escritos sobre os temas estudados. É importante salientar que no diagnóstico que sempre fazemos com nossos alunos no início do ano letivo, deixamos um espaço livre para que eles manifestem a expectativa deles em relação às aulas de Língua Inglesa. Podemos observar que o desejo deles de desenvolver a competência oral é unânime. Portanto, não podemos nos furtar em atender a esse desejo e a essa necessidade dos alunos, conforme defendido também nas Orientações Curriculares do Ensino Médio (BRASIL, 2006). Consideramos tal postura um avanço no texto legal. É importante esclarecer, ainda, que esse texto legal elege a comunicação oral como letramento, ou seja, a língua[gem] como prática sociocultural. Concordamos, ainda, com o que aponta Almeida Filho (2013), para quem a autoria de um livro didático apenas está finalizada com a utilização do material em sala de aula pelos professores e alunos, como intérpretes da obra, flexibilizando a utilização do livro didático para atender às necessidades dos alunos.

Iniciamos, então, o desenvolvimento do projeto, dividindo a turma em grupos, sendo três a quatro alunos por grupo, com uma média de quatro grupos por turma. Para atender aos objetivos do nosso programa de ensino, que busca desenvolver também a proficiência oral com os alunos, conseguimos, em proposta apresentada à coordenação da área de formação geral e à diretoria da instituição há alguns anos, que as turmas de Língua Inglesa fossem divididas em dois subgrupos. Essa forma de organização é também praticada nas aulas de Artes, Informática, Educação Física e nas disciplinas práticas da área técnica dos cursos da instituição. Assim, essas subturmas são geralmente constituídas de vinte alunos em Língua Inglesa. Essa organização do nosso trabalho possibilita que possamos dar assistência individualizada aos alunos e aos grupos.

Os temas do projeto foram divididos entre os grupos, sendo que ficou estabelecido como Tema 1, o levantamento sobre a formação escolar dos pais dos colegas; e como Tema 2, 
a escolha do curso superior pelos colegas. Analisamos os diálogos ${ }^{5}$ apresentados no livro, transcritos logo abaixo. A atividade na íntegra proposta pelo livro didático se encontra nos Anexos A e B.

QUADRO 1 - Diálogos apresentados no livro didático

\begin{tabular}{|l|l|}
\hline $\begin{array}{l}\text { 1. In groups, prepare a few questions to ask your } \\
\text { classmates to fill in the chart below }\end{array}$ & $\begin{array}{l}\text { 2. Now do the same as in exercise } 1 \text { to find out } \\
\text { about your classmates' plans for university. }\end{array}$ \\
\hline A: Do your parents have a university degree? & A: What do you plan do study at university? \\
\hline $\begin{array}{l}\text { B: No, only my mother has a university degree; } \\
\text { my father has a high school diploma. }\end{array}$ & B: Oh, I'd like to study biology. \\
\cline { 2 - 2 } & A: Oh, I see, you like Science, then. \\
\end{tabular}

Fonte: RICHMOND EDUCAÇÃO (2010, v.1, p. 34-35).

A partir destes diálogos, construímos outros diálogos possíveis que os levariam a obter a informação desejada e a responder de forma adequada à entrevista. Em suma, não ficamos circunscritos a apenas reproduzir os diálogos do livro. Essas outras possibilidades ficaram registradas no quadro o que proporcionou segurança aos alunos quando eles iniciaram a conversação em inglês com os colegas, levando-os, dessa maneira, a romperem com o que para eles era um obstáculo, em suma, desenvolvendo a autonomia e a autoconfiança. A tendência de utilizarem a língua portuguesa na atividade foi sendo substituída pelo uso da Língua Inglesa.

Os alunos iniciaram, em seguida, a etapa dois, que era o levantamento de dados, gerados a partir das entrevistas com os colegas dos outros grupos. A fase final seria a apresentação, em inglês, desses dados para a própria turma. Foi disponibilizado o projetor multimídia da instituição e o meu próprio notebook para apresentação dos trabalhos. Algumas salas de aulas da instituição já possuem projetor multimídia instalado, mas nas salas de inglês precisamos montar o equipamento a cada vez que vamos utilizá-lo. Como as salas são específicas para a nossa disciplina, podemos organizar o material antes do início das aulas.

Ao acompanhar os grupos na realização das entrevistas, percebemos que alguns alunos se sentiam desconfortáveis ao terem de informar o nível de escolaridade dos pais, pois havia casos em que um dos pais possuía apenas o certificado de conclusão da escola primária, atual Ensino Fundamental I, e até casos de analfabetismo. Esse fato nos levou a considerar as questões afetivas envolvidas no desenrolar das atividades. Para ajudar esses alunos a se sentirem confortáveis, conversamos com eles à parte e lhes explicamos que não deveriam se envergonhar da formação escolar do pai ou da mãe deles, mas sim, entender o porquê de eles não terem tido acesso nem mesmo à educação básica.

\footnotetext{
5 1.Em grupos, preparem algumas questões para perguntar aos seus colegas e preencham o quadro abaixo. A:Seus pais possuem nível superior? B: Não, apenas minha mãe possui nível superior, meu pai tem o diploma de segundo grau. 2. Agora faça o mesmo que no exercício 1 e descubra os planos de seus colegas para o curso superior. A: O que você pretende estudar na universidade? B: Ah, eu gostaria de estudar biologia. A: Ah, entendo, você gosta de ciências, então. (Tradução nossa).
} 
A etapa três do projeto constituía na organização e apresentação dos dados. Em um primeiro momento, os alunos calcularam as porcentagens das respostas dadas pelos colegas durante a entrevista. Em seguida, redigiram um parágrafo sobre o levantamento que realizaram. O passo seguinte foi a organização dos dados em um diagrama de pizza. Nessa fase, vários alunos apresentaram dificuldade na confecção do diagrama, pois não sabiam utilizar o editor de planilhas eletrônicas. Esse fato nos surpreendeu, pois acreditávamos que, por serem nativos digitais ${ }^{6} \mathrm{e}$ cursarem a disciplina Informática, não teriam problemas para transferir os dados para uma planilha eletrônica. Essa dificuldade dos alunos foi solucionada pela colaboração entre os próprios pares, pois havia colegas que sabiam utilizar o editor de planilhas e ajudaram aqueles que precisaram. Também em relação ao projetor multimídia, houve colaboração entre os pares. O fato de termos solicitado aos alunos que fizessem uso do computador e projetor para organizar e apresentar os dados reflete o que é posto por Kalantzis e Cope (2012) sobre a escrita multimodal como melhor maneira de representar o conhecimento nas diversas áreas do currículo na sociedade digitalizada.

Posteriormente, após a apresentação dos dados da turma, conversamos com os alunos sobre a existência do analfabetismo em pessoas adultas no nosso país - um índice de 8,7\%, correspondente a 13,2 milhões de pessoas, de acordo com o censo de 2012 do Instituto Brasileiro de Geografia e Estatística, IBGE (G1EDUCAÇÃO, 2014). Esse índice foi levemente reduzido para 8,3\% em 2013 (UOL EDUCAÇÃO, 2015). Em um país como o nosso que ostenta uma bandeira letrada - "Ordem e Progresso" - é inadmissível que uma parcela dos seus cidadãos esteja excluída do acesso à educação. Essa parte de debates na aula sobre temas estudados geralmente é conduzida em língua materna, para possibilitar a participação de todos os alunos, devido ao não domínio do vocabulário ou estruturas específicas da Língua Inglesa por todos do grupo. Esses debates propiciaram o desenvolvimento do letramento crítico, previsto nas OCEM (BRASIL, 2006). Segundo Souza (2011), o letramento crítico é uma reflexão sobre como lemos o mundo. O autor pontua que o letramento crítico objetiva ir além do senso comum, fazer o aluno ultrapassar a aparência de verdade, de originalidade, pois os saberes se originam não do eu, mas da coletividade. $\mathrm{O}$ letramento crítico deve ser desempenhado em todas as atividades pedagógicas desenvolvidas por nós. Nas palavras do autor,

O letramento crítico consiste em não somente ler, mas ler se lendo, ou seja, ficar consciente o tempo inteiro de como eu estou lendo, como eu estou construindo significado [...] e não achar que leitura é um processo transparente, o que eu leio é aquilo que está escrito [...]. Pensar sempre: por que entendi assim? Por que acho isso? De onde vieram as minhas ideias, as minhas interpretações? (SOUZA, 2011, p.296).

A avaliação do projeto foi realizada, levando em conta os seguintes critérios: a realização da tarefa, englobando os itens de introdução, desenvolvimento, conclusão e organização do material apresentado; a pronúncia, englobando o acento das palavras e sentenças, o encadeamento dos sons, o uso correto das estruturas gramaticais e expressões

\footnotetext{
${ }^{6}$ Prensky (2001, p.2) utiliza o termo nativo digital para se referir aos alunos que cresceram utilizando as tecnologias digitais. Segundo o autor, os nativos digitais possuem as seguintes características: estão acostumados a receber informação de forma bastante rápida; fazem várias atividades ao mesmo tempo, preferem informações que possam ser facilmente visualizadas em formas de figuras, desenhos, gráficos e que possam ser acessadas de forma aleatória, como o hipertexto, trabalham melhor quando estão interconectados, se desenvolvem melhor quando recebem recompensas rápidas e frequentes e preferem jogos ao trabalho ‘sério’. (Tradução nossa).
} 
aprendidas em aula, e a fluência. Cumpre salientar que, muitas vezes, o aluno quer se expressar de alguma outra forma, às vezes, até mais complexa, que requer o uso de estruturas gramaticais e vocabulário que ainda não foram estudados. Nesse caso, consideramos essa atitude muito salutar, valorizando como tentativas de acerto e não apenas como erro, o que faria com que o mesmo fosse penalizado na nota do trabalho ou da atividade. A avaliação foi realizada, assim, coerentemente com os princípios do processo ensino-avaliaçãoaprendizagem que adotamos na nossa disciplina.

É importante pontuarmos sobre a gestão do tempo envolvido na realização do projeto de trabalho. Planejamos quatro aulas para tal atividade. No entanto, houve turmas em que foram necessárias seis aulas. Trabalhamos sempre com aulas geminadas, o que possibilita otimizar um pouco a pequena carga horária que temos de duas aulas semanais.

\section{Considerações finais}

Ao fazermos uma avaliação retrospectiva e prospectiva do projeto que desenvolvemos, pudemos perceber que a realização do mesmo proporcionou aos alunos, consoante com os objetivos do programa de ensino da disciplina, compreenderem a linguagem como prática social, reconhecendo a diversidade linguística e cultural; engajaremse discursivamente para construir significados em relação ao mundo em que vivem; e desenvolverem habilidades de conversação, leitura e produção textual. Os alunos se sentiram motivados para realizar as atividades propostas. A avaliação foi realizada de forma processual, em que os erros foram fonte de aprendizagem.

Além destes objetivos atingidos, a atividade propiciou um tratamento interdisciplinar com o conteúdo das disciplinas de Matemática e Informática, ao levar os alunos a calcular as porcentagens do nível de escolaridade dos pais dos colegas e dos planos para a escolha do curso superior dos colegas de sala, e a utilizar planilhas eletrônicas, respectivamente. A interdisciplinaridade também foi realizada com o conteúdo de História e Sociologia, ao debatermos as questões históricas e sociais envolvidas no alto índice de analfabetismo no nosso país. Essa discussão levou, também, ao desenvolvimento do letramento crítico, previsto nas OCEM (BRASIL, 2006).

Percebemos, entretanto, algumas lacunas na realização desta atividade. Não houve interação com os professores das outras disciplinas mencionadas, o que poderia ter enriquecido esta experiência. Em relação aos propósitos da avaliação formativa e dos projetos de trabalho, não realizamos a auto-avaliação, que pode auxiliar o aluno no desenvolvimento da autonomia. Também não realizamos a co-avaliação, forma de avaliação em que os colegas avaliam seus pares. Logicamente, os critérios com os quais os alunos avaliariam os seus colegas deveriam ser conhecidos por todos, com antecedência. Como explicitamos, neste texto, as rubricas cumprem essa função de informar os alunos dos critérios utilizados na avaliação da atividade. Essas duas outras formas de avaliação, a auto-avaliação e a coavaliação, são uma forma de fazer com a avaliação não fique centrada apenas na figura do professor, como único avaliador dos trabalhos dos alunos. Ressaltamos que realizamos este 
projeto antes de iniciarmos os nossos estudos de doutorado ${ }^{7}$ em Estudos Linguísticos e de participarmos do Programa ${ }^{8}$ de Desenvolvimento Profissional para Professores de Língua Inglesa, PDPI, quando tivemos a oportunidade de refletir sobre a nossa própria prática avaliativa e, assim, fazermos uma avaliação retrospectiva dessa prática.

A atividade também não ultrapassou os muros da escola. Uma possibilidade de se atingir tal propósito teria sido propor aos alunos que realizassem um levantamento sobre o índice de alfabetização da cidade onde moram. Sobre o outro tema, escolha do curso superior, poderiam ter realizado uma entrevista com alunos de outras séries, da própria instituição, englobando, por exemplo, itens sobre uma possível escolha do curso superior, o porquê da escolha, possíveis pressões/influências advindas da família. Consideramos, contudo, que foi uma atividade bem sucedida porque foi significativa para os alunos. Ao falarem da realidade de suas famílias e de suas aspirações para o futuro, eles perceberam que os conteúdos estudados estão integrados às suas vidas.

\section{Referências}

BRASIL. Ministério da Educação. Lei de Diretrizes e Bases da Educação Nacional: Lei n ${ }^{\circ}$ 9.394, de 20 de dezembro de 1996. 8. ed. Brasília: MEC, 2013.

Ministério da Educação. Secretaria de Educação Média e Tecnológica. PCN+ Ensino Médio - Orientações Educacionais Complementares aos Parâmetros

Curriculares Nacionais. Linguagens, Códigos e suas Tecnologias. Brasília: MEC; SEMTEC, 2002. 244p. Disponível em http://portal.mec.gov.br/seb/arquivos/pdf/linguagens02.pdf. Acesso em 30 jun 2014.

- Ministério da Educação. Secretaria de Educação Básica. Orientações Curriculares para o Ensino Médio. Brasília: MEC/SEB, 2006.

Ministério da Educação. Conselho Nacional de Educação. Câmara de Educação Básica. Parecer CNE/CEB no 5/2011. Diretrizes Curriculares Nacionais para o Ensino Médio. Brasília: MEC/CNE/CEB, 2011.

Brasil é o $8^{\circ}$ país com maior número de analfabetos adultos, diz Unesco. G1 Educação, Rio de Janeiro, 29 jan. 2014. Disponível em http://g1.globo.com/educacao/noticia/2014/01/brasil-e-o-8-pais-commais-analfabetos-adultos-diz-unesco.html. Acesso em 30 set 2014.

Brasil ainda tem 13 milhões de analfabetos com 15 anos ou mais. UOL Educação, Maceió, 18 set. 2014. Disponível em http://educacao.uol.com.br/noticias/2014/09/18/brasil-ainda-tem-13-milhoes-deanalfabetos-com-15-anos-ou-mais.htm. Acesso em 20 maio 2015.

\footnotetext{
${ }^{7}$ No doutorado em Estudos Linguísticos na Universidade Federal de Uberlândia, cursamos a disciplina Tópicos em Linguística Aplicada 2 - Avaliação e Linguística Aplicada, em 2014.

${ }^{8}$ Esse curso foi realizado nos Estados Unidos em 2013. Foi coordenado pela CAPES (Edital n.44/2012), em parceria com a Embaixada dos Estados Unidos no Brasil e com a Comissão Fulbright, com o apoio do Conselho Nacional de Secretários da Educação (Consed) (BRASIL, 2012).
} 
FERNANDES, D. Avaliar para aprender: desafios teóricos e práticos da avaliação pedagógica (formativa e somativa). In: II Seminário Internacional de Avaliação, 2. Seminário Municipal de Avaliação, 1., 2015, Uberlândia. Palestra... Universidade Federal de Uberlândia, 28 abr.2015.

FELICE, M. I. V. O processo ensino-avaliação-aprendizagem de LE. In SARTORI, A. T.; da Silva, S.R. (Org.). Reflexões em Linguística Aplicada: Práticas de Ensino de Línguas e Formação do Professor. Campinas, SP: Pontes Editores, 2013. v. 29, p.47-79.

FIDALGO, S.S. A avaliação de ensino-aprendizagem e as políticas públicas estaduais: uma revisão teórico-prática. Cadernos Cenpec. São Paulo, v.5, n.2, p.284-308. jul. dez. 2015.

HADJI, C. Avaliação Desmistificada. Porto Alegre: Artmed, 2001.

HERNÁNDEZ, F. Transgressão e Mudança na Educação: os projetos de trabalho. Porto Alegre: Artmed, 2008.

KALANTZIS, M.; COPE, B. Literacies. London: Cambridge University Press, 2012.

MÉNDEZ, J.M.A. Avaliar para conhecer, examinar para excluir. Porto Alegre: Artmed Editora, 2002.

MONTE-MOR, W. As políticas de ensino de línguas e o projeto de letramentos. In: NICOLAIDES, C. et al. Política e Política Linguísticas. Campinas, SP: Pontes Editores, 2013. p. 219-236.

NESSRALLA, M.R.D. Avaliação e formação em serviço para professores de língua inglesa da rede pública de ensino: a experiência no PDPI. In: Sobre avaliação e ensino de línguas: (re)discutindo conceitos e (re)elaborando ações. Campinas, SP: Pontes, 2016, p.69-92.

NICOLAIDES, C.; TÍLIO, R. Políticas de ensino e aprendizagem de línguas adicionais no contexto brasileiro: o caminho trilhado pela ALAB. In: NICOLAIDES, C. et al. Política e Política Linguísticas. Campinas, SP: Pontes Editores, 2013. p. 285-306.

PAIVA, V.L.M.O. Inovações tecnológicas: o livro e o computador. In: VETROMILLECASTRO, Rafael; HEEMANN, Christiane; FIALHO, Vanessa Ribas. Aprendizagem de línguas: CALL, atividade e complexidade. Uma homenagem aos 70 anos do Prof. Dr. Vilson José Leffa. Pelotas: Educat, $2012 . \quad$ Disponível em http://www.veramenezes.com/vilson.pdf. Acesso em 23 jun. 2014.

PRENSKY, M. Digital Natives, Digital Immigrants. On the Horizon. Bingley: MCB University Press, 2001, v.9, n.5.

RICHMOND EDUCAÇÃO (Org.). Freeway: Manual do Professor. São Paulo: Richmond Educação, 2010.v.1. p.34-35.

ROJO, R. Materiais didáticos no ensino de línguas. In: MOITA LOPES. Linguística Aplicada na Modernidade Recente: Festschrift para Antonieta Celani. São Paulo: Parábola Editorial, 2013. Cap. 7. p.163-195.

SILVA, J. F. da. Introdução: Avaliação do Ensino e da Aprendizagem numa Perspectiva Formativa Reguladora. In: SILVA, J. F., HOFFMANN, J., ESTEBAN, M. T. (Org). Práticas 
Avaliativas e Aprendizagens Significativas. 4 ed. Porto Alegre: Editora Mediação, 2006, p.7-18. 


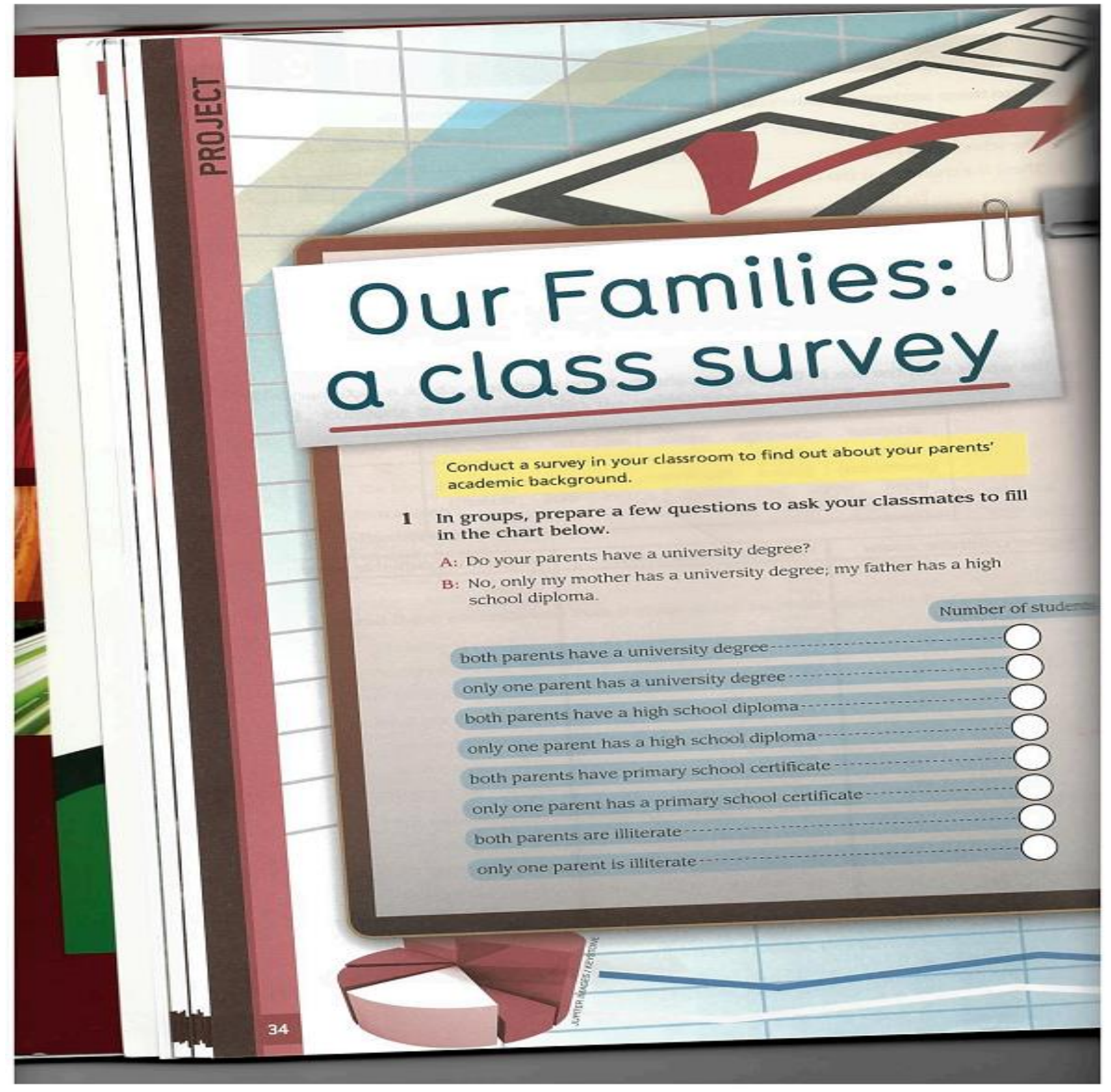

RICHMOND EDUCAÇÃO (Org). Freeway: Manual do Professor. São Paulo: Richmond Educação, 2010. V.1. p.35. Reprodução autorizada. 


\section{ANEXO B}

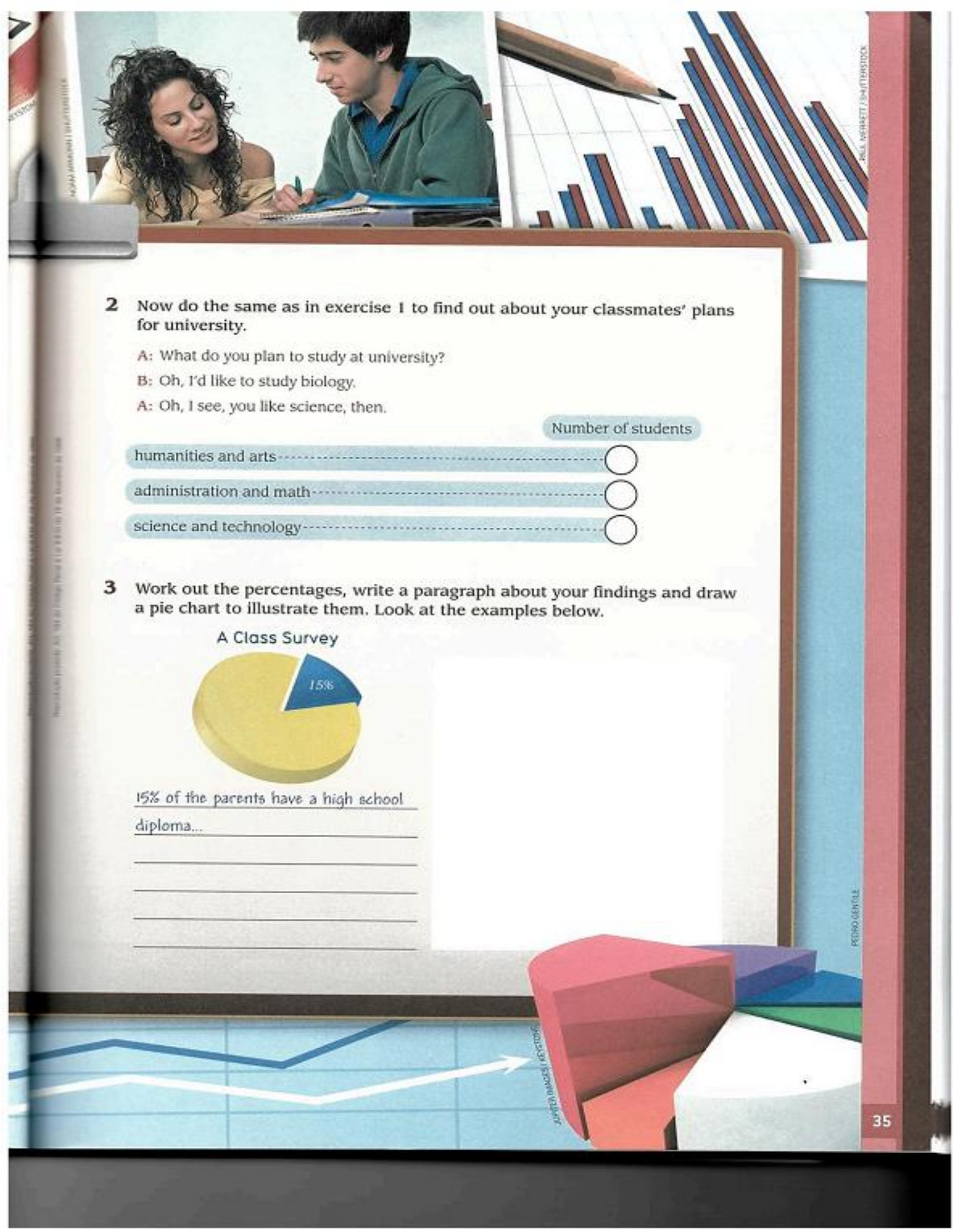

RICHMOND EDUCAÇÃO (Org). Freeway: Manual do Professor. São Paulo: Richmond Educação, 2010. V.1. p.35. Reprodução autorizada. 